\title{
A CALL FOR MORE SOCIOMATERIALITY AND ITS USAGE IN RESEARCH ON DIGITAL TRANSFORMATION
}

\author{
Sven Packmohr \\ Malmö University, Dept. of Data Science and Media Technology (DVMT) \\ Nordenskiöldsgatan 1, 21119 Malmö, Sweden
}

\begin{abstract}
Sociotechnical and sociomaterial perspectives are tools for research on Information System. As Digital Transformation is a research area related to IS, this paper takes these two perspectives into account for a literature review. The explicit use of both perspectives is rather limited. Still, sociotechnical is the broader perspective. A call for more sociomateriality in research on Digital Transformation is the aim of this reflection paper.
\end{abstract}

\section{KEYWORDS}

Sociotechnical, Sociomaterial, Digital Transformation

\section{INTRODUCTION}

Although digital transformation (DT) is a rather young field, recent reviews found 73,244 publications in the realm of management literature dating 20 years back (Hausberg et al., 2019). Other reviews claim a superior amount of case studies as research methods (Reis et al., 2018). The latter shows the maturity of the field, which seems to be in the phase of exploration. DT can be seen as a further development of the use of information systems. For research on information systems and organization, Orlikowski and Scott (2008) propose sociomateriality to develop the field in research further.

This paper reflects upon sociomateriality as a perspective for research in the field of DT. Therefore, the research questions are: How is sociomateriality used in research on DT? How can sociomateriality be framed better to help researchers in applying this perspective in research on DT?

To conclude, short introductions on the terms sociomateriality and digital transformation are given. A literature search is conducted to present how common combinations of these two and related terms are. The results from the search are the base for the later discussion and conclusion.

\section{SOCIOMATERIALITY}

Leonardi (2012) defines and relates different concepts in the realm of sociomateriality. Sociotechnical system (STS) is the older term coined by Trist and Bamforth. They argue for an interrelation of technological and social systems. The STS approach became common in IS and organizational studies (Cecez-Kecmanovic et al., 2014). As the older and broader term, STS is the general recognition of a non-simultaneous interconnection between social and technical elements on an abstract level. Whereas sociomateriality is the specific "enactment of a particular set of activities that meld materiality with institutions, norms, discourses, and all other phenomena we typically define as 'social' ". A prerequisite for this is materiality. Materiality is defined as the composition of a technological system (artifact). Such a system contains features, which are somewhat stable over time and significant to users. Sociomateriality is the imbrication of the social agency and the material agency, which influences the social subsystem and is influenced by it (Leonardi, 2012). 


\section{DIGITAL TRANSFORMATION}

Reis et al. (2018) review and analyze different definitions of Digital Transformation (DT). According to the smallest common meaning, DT uses "new digital technologies that enable major business improvements and influences all aspects of customers' lives." This definition shows three elements: (1) technology, (2) organization, (3) customer.

DT is a relatively new field. Although first publications date back to 1968, it is first around 2015 that it became a topic of interest in academic research.

Digital Transformation includes technology such as Information Systems (IS). Nolan and Wetherbe (1980) define IS as an "integrated, man/machine system for providing information to support the operation, management, and decision-making functions in an organization." O'Brien and Marakas (2011) add data input, processing, and output of information products.

\section{USAGE OF BOTH PERSPECTIVES IN THE ACADEMIC LITERATURE}

The author conducted different searches via the Scopus database by the beginning of 2020. The aim is to get an impression of how the usage of a sociomaterial perspective evolves in literature. The searches focus on the article's title, abstract, and keywords. The first search on DT and sociomateriality found only one article by Barata and Da Cunha (2018). The sociotechnical counterpart generated 43 results. Sometimes, the terms sociomateriality and sociotechnical are spelled with a hyphen. Although some authors call for spelling without a hyphen, both versions were included in the search. Otherwise, no time, language, or other limits were set.

A broader search and included both American and English spelling of digitali(z/s)ation leading to 8 new results and a total of 9 resources. The sociotechnical counterpart generated 115 results.

As the term digital transformation is rather new, the author conducted searches on organi(z/s)ation and IS. Primarily, search number 8 would need some refinement. Areas like health-care and farming show up, in which sociotechnical imaging / sociotechnical imaginaries are addressed. These terms address a system thinking, too. They do not necessarily include information systems.

Therefore, searches number 9 and 10 were conducted. These searches show the overlap between searches on organization and IS. The search results show the dominance of the sociotechnical view.

Table 1. Scopus search results

\begin{tabular}{rll}
\hline$\#$ & Search string & Results \\
\hline 1 & "digital transformation" AND (sociomateriality OR socio-materiality) & 1 \\
2 & "digital transformation" AND (sociotechnical OR sociotechnical) & 43 \\
3 & $\begin{array}{l}\text { ("digital transformation" OR digitalization OR digitalisation) AND } \\
\text { (sociomateriality OR socio-materiality) }\end{array}$ & 9 \\
4 & $\begin{array}{l}\text { ("digital transformation" OR digitalization OR digitalisation) AND } \\
\text { (sociotechnical OR sociotechnical) }\end{array}$ & 115 \\
5 & "information systems" AND (sociomateriality OR socio-materiality) & 157 \\
6 & "information systems" AND (sociotechnical OR sociotechnical) & 1703 \\
7 & (organization OR organisation) AND (sociomateriality OR socio-materiality) & 150 \\
8 & (organization OR organisation) AND (sociotechnical OR sociotechnical) & 2644 \\
9 & $\begin{array}{l}\text { (organization OR organization) AND ("information systems") AND } \\
\text { (sociomateriality OR socio-materiality) }\end{array}$ & 57 \\
10 & $\begin{array}{l}\text { (organization OR organization) AND ("information systems") AND } \\
\text { (sociotechnical OR sociotechnical) }\end{array}$ & 571 \\
\hline
\end{tabular}

The following section will summarize the resources found in the third search to overview the kinds of research and the applied procedures.

Klischewski (2019) addresses the issue that information systems become more and more autonomous. The author uses a sociomaterial perspective to research the interconnection between human action and technology performance in the area of digitalized governmental systems. Drawing on models from 
Mintzberg, challenges are identified. A way to solve the marginalization of humans is a more aligned composition of the system, reflecting the human and the machine agency.

Knights and Latham (2019) research the distribution of computers for social interactions given to disabled people by using a case study design. The selection procedure is administrated by an allocation assessment form. The authors analyze how the form, the allocation procedure, the distributors, and the solicitors influence each other.

Barat and Da Cunha (2018) examine the transformation of traditional industries towards Industry 4.0 as it claims a new perspective on the social and the material. The authors use an action research approach to explore how product life-cycles evolve through the social and the material. The results are aggregated into roadmaps.

Morland and Pettersen (2018) aim to understand how clinical work is changed by technology and the usage of medical personal. In a case study, the authors analyze the use of a speech recognition system through the lenses of an actor-network theory approach. Results show the importance of powerful actors and their influence on system development and usage.

Samdanis and Lee (2017) use a case study of a leading architect to investigate the interplay between technology and architects. This interplay influences how space is designed and experienced. Results show the importance of uniqueness as well as the development of a personal digital system for design.

Furthermore, power relations play an essential role in developing digital materiality. Bader and Kaiser (2017) look more in-depth into paradoxes provoked by an interplay between technology and individuals, such as greater autonomy and greater control. The authors examine different degrees of the autonomy-control paradox, which are (1) independence of autonomy and control, a (2) hybrid degree on an individual level, or (3) dominance of one aspect. The hybrid paradox on the individual level is influenced by social norms. This research informs managers who seek to influence specific rationalities in paradoxes.

Panourgias, Nandhakumar, and Scarbrough (2014) research how the interplay between creativity and digital technology shapes the development of computer games. The researchers use data from three leading development studios to show how new development technologies and development practices influence creativity and are influenced by creativity. In this work, creativity is understood as a process triggered by a creative starting event.

Hedman, Srinivasan, and Lindgren (2013) survey literature in leading IS journals to analyze how researchers work with data on digital traces. For this, they developed a classification for data. Their results show that digital data-traces are underused. They suggest being more aware of these data sources as they are the result of a sociomaterial process.

For their panel, Barret et al. (2012) connect service innovation and digitization to focus the panelist perspective onto the multiple contexts of a service exchange between customers and suppliers. It leads to a paradigm shift if the social-material and tangible-tacit dynamics of exchange are considered for concepts and models of service-design.

\section{DISCUSSION}

Table 1 shows that a sociotechnical perspective is more common in research than sociomateriality. This might seem logical for the literature search in the fields of information systems and organizations. These fields are more mature and had more time to develop a sociotechnical perspective as it is the older term. When looking at DT, which is a younger research area, the same pattern applies. Potentially, the number of results between both terms could be distributed equally. Both terms were known in epistemology when research on DT got on track. Still, the focus is on research addressing a sociotechnical perspective. Although DT is not that mature as the field of organization or information systems, researchers might feel more used to the sociotechnical view. Critics claim that sociomateriality has some drawbacks, such as a lack of understandability of certain information systems (Mutch, 2013). It might help to induce sociomateriality into a broader picture. (Creswell, 2013) proposes a dependency on the researchers' perspective and experience with philosophical assumptions and interpretative frameworks. This leads to research strategies and approaches, which, in return, lead to methods of data collection and analysis. In the end, all these levels influence the practices of interpretation and evaluation. If sociomateriality and STS could be placed in this model in a coherent way, it might help researchers in getting more familiar with these terms. The resources in 
section 4 show that some studies follow a case study or an action research approach. Such as Panourgias, Nandhakumar, and Scarbrough (2014), who ask the following research question concerning sociomateriality: "How does a focus on the 'sociomaterial entanglements' of human and material agencies enhance our understanding of this interaction between the creative agency and the design of digital technologies?" A research question is influenced by the researching subject as well as her/his philosophical assumptions and interpretative frameworks. (Creswell, 2013) lists nine frameworks. Out of these nine, four are focusing on the empowerment of marginalized groups, leaving five frameworks that might be applicable for DT research, which are post-positivism, constructivism, transformative/postmodern, and pragmatism. Looking upon ontology, epistemology, axiology, and methodology, it seems sociomateriality fits best with constructivism. Thus, interactions with technologies need to be included in this framework. Although, some authors question the fit of a constructivist framework (Orlikowski and Scott, 2008). Sociomateriality could become part of the researching subjects' beliefs (Creswell, 2013) that individuals and technology are part of an interdependency. Beliefs and experiences take a longer time to change. This might also be an argument for less sociomateriality in research in general.

Another aspect is bound to different types of research. Descriptive research clarifies the characteristics of a phenomenon. In comparison, normative research explains how a certain status evolves (Meirovich, 2015). A description of a specific phenomenon can be done on a very aggregated level. E.g., without looking at certain technologies in detail. With normative research, a black-box perspective, e.g., on technology, will less likely generate reliable results. For normative frameworks within DT, the digital aspects need to be materialized within research projects. Here, researchers can draw insights from a design point of view. Some of the reviewed resources take a design view into account. These design insights found entry to IS research already (Chandra, Seidel, and Gregor, 2015). Therefore, a call to adopt a sociomaterial perspective in research on DT is needed.

\section{CONCLUSION AND OUTLOOK}

Results show that sociomateriality lacks behind. Researchers use this perspective less than the sociotechnical perspective. Sociomateriality could give valuable insights. DT, as a new field, gives the chance to experiment with more sociomateriality-focused approaches. In DT, three views come together, making it more complex. This complexity opens up for an even more entangling approach.

This reflective paper gives first insights on sociomateriality in the field of DT. A more comprehensive model on how to specifically use sociomateriality needs to be developed. A start is to work backward from existing publications and evaluate in greater detail how sociomateriality fits into models of a research process and how normative perspectives can evolve (Creswell, 2013). Furthermore, this preliminary and descriptive literature review could be developed into a broader systematic review, including more induction and interpretation of the results to compare, oppose or complement arguments (Petticrew and Roberts, 2006).

\section{REFERENCES}

Bader, V. and Kaiser, S. (2017) 'Autonomy and Control? How Heterogeneous Sociomaterial Assemblages Explain Paradoxical Rationalities in the Digital Workplace', Management Review, 28(3), pp. 338-358.

Barata, J. and Da Cunha, P. R. (2018) 'Understanding sociomaterial transformations in industry 4.0: An action research study', in Proceedings of the Thirty-Ninth International Conference on Information Systems (ICIS), San Francisco.

Barrett, M. et al. (2012) 'Being innovative about service innovation: Service, design and digitalization', in Proceedings of the Thirty-Third International Conference on Information Systems (ICIS), Orlando.

Cecez-Kecmanovic, D. et al. (2014) 'The Sociomaterialty of Information Systems: Current Status, Future Directions', MIS Quarterly, 38(3), pp. 809-830.

Chandra, L. et al. (2015) 'Prescriptive Knowledge in IS Research: Conceptualizing Design Principles in Terms of Materiality, Action, and Boundary Conditions', in Proceedings of the 48th Hawaii International Conference on System Sciences (HICSS), pp. 4039-4048.

Creswell, J. W. (2013) Qualitative inquiry and research design: choosing among five approaches. 3rd ed. Los Angeles: SAGE Publications. 
Hausberg, J. P. et al. (2019) 'Research streams on digital transformation from a holistic business perspective: a systematic literature review and citation network analysis', Journal of Business Economics, 89(8-9), pp. 931-963.

Hedman, J. et al. (2013) 'Digital traces of information systems: Sociomateriality made researchable', in Proceedings of the Thirty-Fourth International Conference on Information Systems (ICIS), Milan.

Klischewski, R. (2019) 'Will the Government Machine Turn into a Monster?', in 20th Annual International Conference on Digital Government Research, Dubai, United Arab Emirates: ACM Press, pp. 306-313.

Knights, D. and Latham, Y. (2019) 'Disabled People and Digitalization: Disruptive documents in distributing digital devices', Organization Studies, 41(6), pp. 855-872.

Leonardi, P. M. (2012) 'Materiality, Sociomateriality, and Socio-Technical Systems: What Do These Terms Mean? How are They Related? Do We Need Them?', in Leonardi, P. M. et al. (Eds.), Materiality and Organizing: Social Interaction in a Technological World. Oxford: Oxford University Press, pp. 25-48.

Meirovich, G. (2015) 'Normative and Descriptive Aspects of Management Education: Differentiation and Integration', Journal of Educational Issues, 1(1), pp. 97-113.

Morland, C. and Pettersen, I. J. (2018) 'Translating technological change - implementing technology into a hospital', International Journal of Productivity and Performance Management, 67(6), pp. 1000-1015.

Mutch, A. (2013) 'Sociomateriality — Taking the wrong turning?', Information and Organization, 23(1), pp. $28-40$.

Nolan, R. L. and Wetherbe, J. C. (1980) 'Toward a Comprehensive Framework for MIS Research', MIS Quarterly, 4(2), pp. 1-19.

O'Brien, J. A. and Marakas, G. M. (2011) Management information systems. New York: McGraw-Hill.

Orlikowski, W. J. and Scott, S. V. (2008) 'Sociomateriality: Challenging the Separation of Technology, Work and Organization', The Academy of Management Annals, 2(1), pp. 433-474.

Panourgias, N. S. et al. (2014) 'Entanglements of creative agency and digital technology: A sociomaterial study of computer game development', Technological Forecasting and Social Change, 83, pp. 111-126.

Petticrew, M. and Roberts, H. (2006) Systematic Reviews in the Social Sciences: A Practical Guide. Oxford: Blackwell Pub.

Reis, J. et al. (2018) 'Digital Transformation: A Literature Review and Guidelines for Future Research', in Rocha, Á. et al. (eds) Trends and Advances in Information Systems and Technologies. Cham: Springer International Publishing, pp. 411-421.

Samdanis, M. and Lee, S. H. (2017) 'White space and digital remediation of design practice in architecture: A case study of Frank O. Gehry', Information and Organization, 27(2), pp. 73-86. 